\title{
Microstructure Evolution of $\mathrm{Si}$ Nanocrystals in $\mathrm{Si} / \mathrm{C}$ Multilayer Films
}

\author{
Chang Gengrong ${ }^{1}, \quad$ Liu Mingxia ${ }^{1}, \quad$ Ma Fei $^{2}, \quad$ Fu Fuxing ${ }^{1}, \quad$ He Binfeng $^{1}, \quad$ Xu Kewei $^{1,2}$ \\ ${ }^{1}$ Provincial Key Laboratory for Surface Engineering and Remanufacturing, Xi'an University, Xi'an 710065, China; ${ }^{2}$ State Key Laboratory for \\ Mechanical Behavior of Materials, Xi'an Jiaotong University, Xi'an 710049, China
}

\begin{abstract}
Si} / \mathrm{C}$ multilayer films deposited by radio frequency magnetron sputtering were post-annealed at $1100{ }^{\circ} \mathrm{C}$ for $1 \mathrm{~h}$ to produce Si nanocrystals (NCs). X-ray diffraction and Raman spectroscopy were used to analyze the phase composition and atomic vibration spectrum of the multilayer structure. High-resolution transmission electron microscopy was employed to verify the existence of $\mathrm{Si}$ NCs and to observe their sizes and morphologies. The results reveal that the Si NCs are formed by solid-phase recrystallization of the nanometer-thick layers of amorphous Si confined between C layers. The NC shape and size could be tuned by changing the modulation ratio of the Si layer and the $\mathrm{C}$ layer. When the ratio shifts from 0.5 to 2 , the NCs become spherical, elliptical, square, or brick-shaped. This growth mode may be conducive to the design of different Si-based photo-electronic materials.
\end{abstract}

Key words: silicon nanocrystal; Si/C superlattice film; microstructure; Raman shift

The use of silicon nanocrystals ( $\mathrm{Si} \mathrm{NCs)} \mathrm{is} \mathrm{considered} \mathrm{an}$ effective method to engineer the bandgap of Si materials ${ }^{[1-3]}$. The fundamental study of Si NCs has suggested various potential applications for Si NCs, such as semiconductor light emitter ${ }^{[4,5]}$, solar photovoltaic system ${ }^{[6-8]}$, and non-volatile memory devices ${ }^{[9-11]}$. Researchers have demonstrated that the bandgap of Si NCs increases with decreasing NC size; hence, smaller NCs absorb more optimal photons ${ }^{[2,5]}$. The two most common methods used to produce Si NCs include the incorporation of Si NCs in a dielectric matrix ${ }^{[12,13]}$ and alternating layers of a Si-rich dielectric and a stoichiometric layer of dielectric ${ }^{[2,9,14]} \cdot \mathrm{SiO}_{2}$, $\mathrm{Si}_{3} \mathrm{~N}_{4}$ and $\mathrm{SiC}$ are considered suitable dielectric matrices; among them, $\mathrm{SiC}$ provides lower barriers than $\mathrm{SiO}_{2}$ and $\mathrm{Si}_{3} \mathrm{~N}_{4}$ allowing more quantum confinement for a given dot spacing $^{[6]}$. In addition, a prerequisite to achieve good quantum confinement and optoelectric performance is the ability to control the size, shape, and density of Si NCs ${ }^{[14,15]}$. Si NC size and density are often controlled by varying the stoichiometry of the films ${ }^{[9,13,16]}$; films with a higher amount of Si produce larger, randomly distributed Si NCs, which are typically non-spherical or agglomerated. The size, shape, and density are not independent on each other; the primary challenge is independently co-regulating two of them with good controllability.

Recent studies have indicated that multilayer film structures (superlattice structures) such as $\alpha-\mathrm{SiO}_{x} / \mathrm{SiO}_{2}{ }^{[2]}$, $\mathrm{SiN}_{x} / \mathrm{Si}_{3} \mathrm{~N}_{4}{ }^{[13]}$, and $\alpha-\mathrm{Si}_{1-x-y} \mathrm{C}_{x} \mathrm{O}_{y} / \mathrm{H}-\alpha-\mathrm{SiOC}^{[14]}$ allow effective control of size and density. Because of the relatively lower barrier height of amorphous $\operatorname{SiC}(\alpha-\operatorname{SiC})$, the tunneling probability of carriers between NCs (Si NC size $<7 \mathrm{~nm}$ in diameter) strongly depends on the barrier height of the host material. Thus, Si NCs embedded in an $\alpha$-SiC dielectric are of considerable interest. Song et al. prepared amorphous $\mathrm{Si}_{1-x} \mathrm{C}_{x} / \mathrm{SiC}$ multilayer films, and $\mathrm{Si}$ NCs were formed after annealing treatment ${ }^{[17]}$. Furthermore, Kurokawa et al. prepared $\alpha-\mathrm{SiC} / \alpha-\mathrm{Si}_{1-x-y} \mathrm{C}_{x} \mathrm{O}_{y}$ superlattices for $\mathrm{Si} \mathrm{NCs}$ and introduced oxygen atoms to develop the $\alpha$-SiC phase ${ }^{[18]}$ and confirmed that the absorption coefficient was enhanced. Simultaneously, Ding et al.

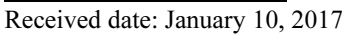

Foundation item: Xi'an Science and Technology Plan Projects (CXY1531WL05); Provincial Science and Technology Projects (2016KTCQ01-80); Provincial Education Department Project (16JK2201)

Corresponding author: Chang Gengrong, Ph. D., Provincial Key Laboratory for Surface Engineering and Remanufacturing, Xi'an University, Xi'an 710065, P. R. China, Tel: 0086-29-88258551, E-mail: gr_chang@163.com 
prepared an $\alpha-\mathrm{SiC}_{\mathrm{SiO}}$ hetero-superlattice, and the precipitation and crystallization of Si NCs took place in the oxide layer $^{[19]}$. In these studies, Si NC size and density could be adjusted by changing the thickness and stoichiometry of the Si-rich dielectric. However, Si NCs stemmed from $\mathrm{Si} / \mathrm{C}$ multilayer films is rarely discussed.

In previous works, we demonstrated that $\mathrm{Si} \mathrm{NCs}$ embedded in an $\alpha$-SiC dielectric can be formed by annealing treatment of a single Si-rich $\mathrm{SiC}$ precursor layer ${ }^{[20]}$. In this work, Si NCs embedded in an $\alpha$-SiC dielectric layer were prepared by the alternating deposition of $\mathrm{Si}$ and $\mathrm{C}$ multilayers, followed by post-annealing treatment. This method provides good control of Si NC growth because the Si NC size is only constrained by the thickness of the Si layer, unlike in the case of Si NCs in a Si-rich dielectric matrix. Herein we report the influence of the $\mathrm{Si} / \mathrm{C}$ modulation ratio $(\zeta)$ on the structural evolution of $\mathrm{Si} \mathrm{NCs}$ in an $\alpha$-SiC dielectric. The obtained structure was characterized and discussed by various techniques to reveal the easy controllability of size and shape.

\section{Experiment}

$\mathrm{Si} / \mathrm{C}$ multilayer thin films were deposited by the alternating magnetron sputtering of $\mathrm{Si}$ and $\mathrm{C}$ targets (diameter $=50.8 \mathrm{~mm}$, purity $=99.99 \%$ ) at a typical base pressure of $7.4 \times 10^{-5} \mathrm{~Pa}$. A RF power supply of $90 \mathrm{~W}$ was applied for sputtering the Si target and a DC power supply of $100 \mathrm{~W}$ was applied for the $\mathrm{C}$ target. The deposition was performed on $\mathrm{Si}(100)$ substrates in the order of $\mathrm{C} / \mathrm{Si} / \mathrm{C} / \mathrm{Si} /$ $/ \mathrm{C}$ at a deposition rate of $4 \mathrm{~nm} / \mathrm{min}$. A series of samples with different modulation ratios were fabricated by varying the thickness of the Si layer while maintaining the $\mathrm{C}$ layer thickness at $10 \mathrm{~nm}$ (Table 1). All samples were then annealed in $\mathrm{N}_{2}$ atmosphere at $1100{ }^{\circ} \mathrm{C}$ for $1 \mathrm{~h}$, and the temperature rise/drop rate was maintained at $25^{\circ} \mathrm{C} / \mathrm{min}$. The crystalline phase was investigated using a MAXIMAX XRD-7000S/L X-ray diffractometer operated in grazing angle mode $\left(\alpha=1^{\circ}\right)$ with an incident X-ray wavelength of $0.154 \mathrm{~nm}(\mathrm{Cu} \mathrm{K} \alpha$ line $)$ at $40 \mathrm{kV}$ and $40 \mathrm{~mA}$. High- resolution

Table 1 Modulation ratio $(\zeta)$ of all sample

\begin{tabular}{cc}
\hline Sample No. & Modulation ratio $\left(\zeta=t_{\mathrm{Si}} / t_{\mathrm{C}}\right)$ \\
\hline I & 0.25 \\
II & 0.5 \\
III & 0.7 \\
IV & 0.8 \\
V & 1 \\
VI & 1.25 \\
VII & 1.5 \\
VIII & 1.75 \\
IX & 2 \\
\hline
\end{tabular}

transmission electron microscopy (HRTEM) cross-sectional observation was undertaken using a JEOL JEM-2010 electron microscope with a $200 \mathrm{kV}$ field-emission gun. Raman spectra were collected using SPEX/403 system with a $514.5 \mathrm{~nm} \mathrm{Ar}^{+}$laser for excitation.

\section{Results and Discussion}

Fig.1 shows the grazing incident X-ray diffraction (GIXRD) patterns of the samples after annealing. All the samples are amorphous (mainly $\alpha-\mathrm{Si}$ and $\alpha-\mathrm{C}$ ) before annealing, and the samples with $\zeta$ smaller than 1 remain amorphous (mainly $\alpha$-SiC) even after annealing (Fig.1a). However, the diffraction peak of Si (111) and the hump of $\alpha$-SiC appear simultaneously at $\zeta=1$. At $\zeta=1.25$, three broad but clear Si diffraction peaks appear corresponding to the (111), (220), and (311) crystal planes. Upon further increasing $\zeta$, the intensities of these diffraction peaks gradually increase (Fig.1b). This trend indicates that some amount of amorphous $\mathrm{Si}$ reacts with $\mathrm{C}$ to $\alpha$-SiC and the remaining amount begins to form $\mathrm{Si} \mathrm{NCs}$; annealing further increases the degree of Si crystallinity. At the same time, the density of the Si NCs increases with increasing $\zeta$. In the XRD patterns, no diffraction peaks are attributed to crystalline $\mathrm{SiC}$ or crystalline forms of $\mathrm{C}$.

On the basis of the GIXRD results, the formation of $\mathrm{Si}$ NCs starts from sample $\mathrm{V}(\zeta=1)$. In order to observe the morphological development, HRTEM analysis was performed on representative samples II, III, V, and IX. Fig.2a shows the cross-sectional image and the selected-area electron diffraction (SAED) pattern of the as-deposited sample IX. The sample is homogeneous, and the SEAD pattern indicates an amorphous aureole. For sample II $(\zeta<1)$, the cross-section is amorphous, and no $\mathrm{Si}$ NCs are observed (Fig.2b). Upon increasing $\zeta$ to 0.7 (sample III), very few NCs with sizes ranging from 2 to 3 $\mathrm{nm}$ are observed (Fig.2c). When $\zeta$ increases to 1 , the density of Si NCs increases obviously (Fig.2d), and the SEAD pattern presents distinct diffraction rings of Si NCs. The two regions indicated by red and yellow boxes in Fig. 2d were observed by HRTEM (Figs.2e and f). The Si $\mathrm{NC}$ layers are separated by amorphous interlayers resulting from $\alpha$-SiC from $\mathrm{C}$ and some amount of Si (Fig.2e), and the $\mathrm{Si}$ NC layers mainly consist of spherical NCs with independent single-crystal structures. Some square Si NCs with lateral and vertical dimensions of $10 \sim 20 \mathrm{~nm}$ and $3 \mathrm{~nm}$, respectively, can also be observed (Fig.2f).

When $\zeta$ exceeds 1.5 , a distinct interface between the $\mathrm{Si}$ NC layers and $\alpha$-SiC interlayers can be observed. Meanwhile, the Si NC layers contain well-defined, brick-shaped NCs with lateral and vertical dimensions of $50 \sim 120$ and $10 \mathrm{~nm}$, respectively. Sample XI is taken as an example (Fig.3). Fig.3a displays a low-magnification image with SAED pattern. The Si NC layer consists mainly of 

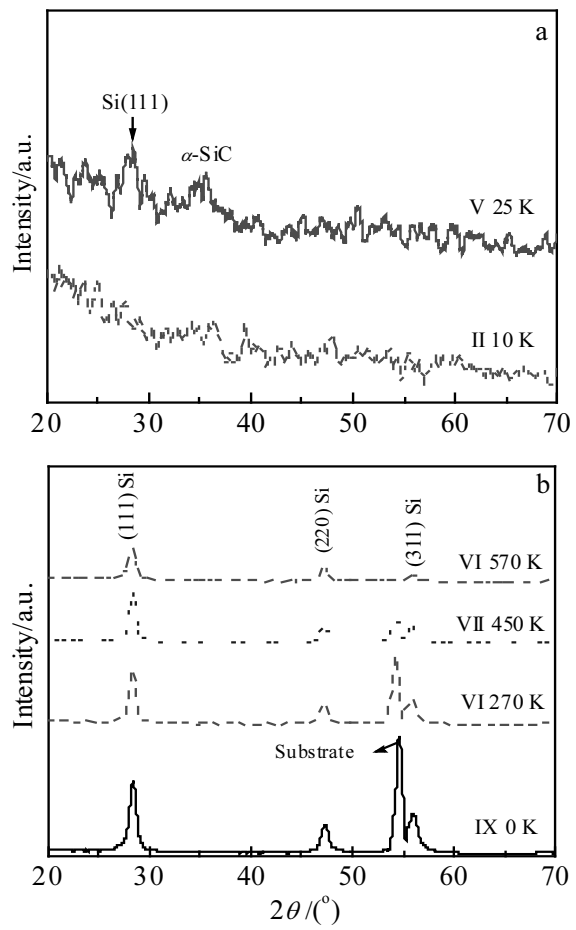

Fig.1 GIXRD patterns of typical samples after annealing: (a) samples II and V and (b) samples VI-IX square $\mathrm{Si} \mathrm{NCs}$, and the $\alpha-\mathrm{SiC}$ interlayers appear to be almost equally planar. Fig. $3 \mathrm{~b}$ and $3 \mathrm{c}$ show the details of the interface and the brick-shaped Si NCs, respectively. Note that there are many parallel, coherent twin-crystal boundaries within the brick-shaped Si NCs (blue line in Fig.3c), and the distance between the twin-crystal boundaries is about $3 \sim 4 \mathrm{~nm}$. Heitmann ${ }^{[9]}$ suggested that the presence of the twin-crystal boundaries can be attributed to a birth defect in the as-deposited amorphous $\mathrm{Si}$ layer. According to the above analysis, the growth pattern of adaptative Si NCs can be ascribed to the confinement of $\alpha$-SiC interlayers, i.e., 2D-confined self-adaptive growth. Because of the $\alpha$-SiC interlayer, amorphous Si layers crystallize and grow along the same layer to form Si NCs but do not traverse up and down. The $\alpha$-SiC interlayer plays a critical role, which realizes the confinement effect and further facilitates the self-adaptive growth of Si NCs.

Seemingly brick-shaped Si NCs with lengths of $100 \mathrm{~nm}$ and thicknesses of $10 \mathrm{~nm}$ were also observed in the region indicated by the red dashed line in Fig.3a. The fast Fourier transformation (inset in Fig.3d) indicates an epitaxial relationship between the brick-shaped $\mathrm{Si}$ NCs and $\mathrm{Si}(111)$ substrates. The Si NCs retain their single-crystal structures without any twin defect. In fact, the natural $\mathrm{SiO}_{2}$ amorphous layer on the $\mathrm{Si}(111)$ substrate plays a decisive role. The $\mathrm{SiO}_{2}$ layer reacts with the first $\mathrm{C}$ layer to form the

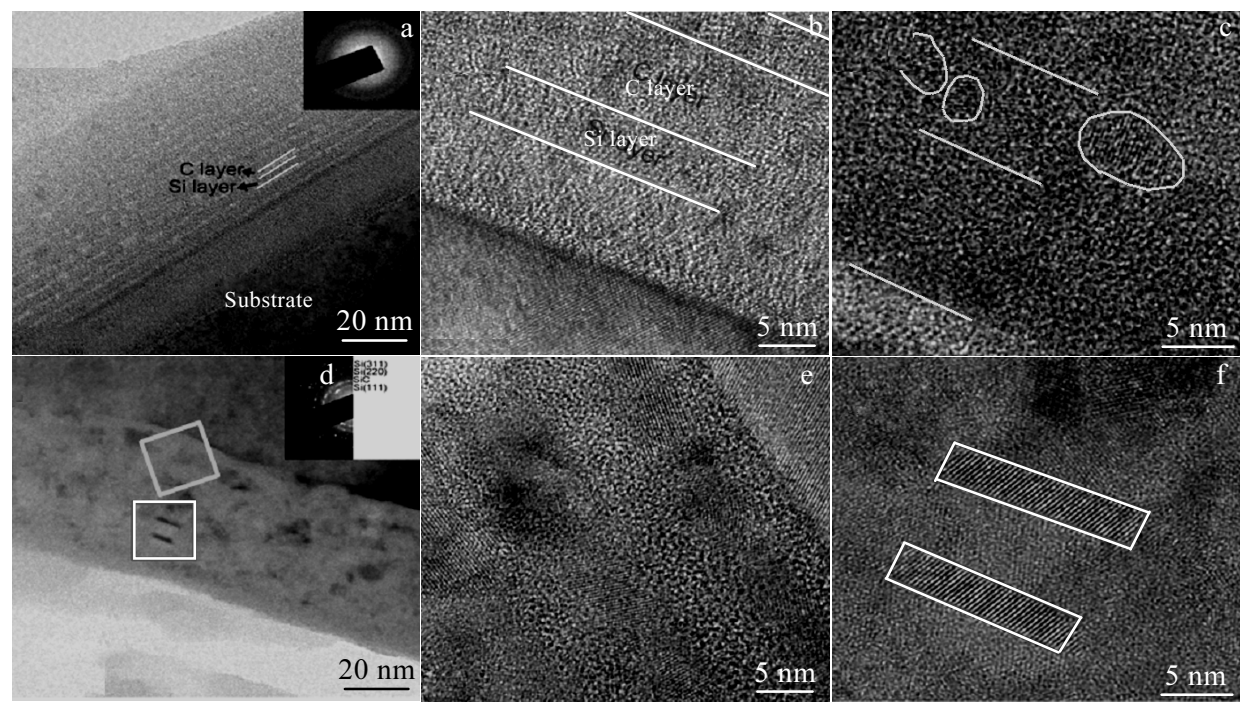

Fig.2 Cross-sectional HRTEM images: (a) as-deposited sample XI, (b) annealed sample II, (c) annealed sample III, and (d f) annealed sample V

brick-shaped Si NCs at high temperature. This result is expected to provide a new method to epitaxially grow $\mathrm{Si}$ NCs.

First-order Raman spectra are very sensitive to local atomic arrangements and lattice vibrations; thus, they have often been used to characterize Si NCs ${ }^{[15-19]}$. Here Raman analysis can further confirm the self-adaptive growth of $\mathrm{Si}$ NCs in Si/C multilayer films. Fig. $4 \mathrm{a}$ and $4 \mathrm{~b}$ show the first-order Raman spectra of the post-annealed samples (curves I-IX). For samples with $\zeta$ lower than 1 (samples I-IV), the humped peaks at about 420 and $800 \mathrm{~cm}^{-1}$ may be attributed to the transverse optical mode of $\alpha$-SiC, while the 


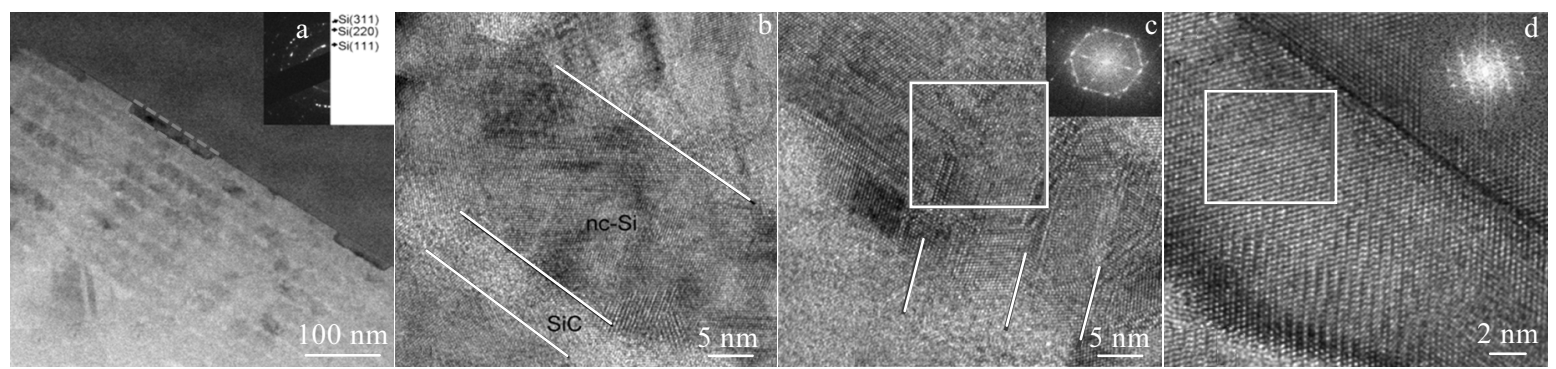

Fig.3 Cross-sectional HRTEM images of annealed sample IX: (a) low magnification with SAED pattern (inset), (b) low magnification, (c) brick-shaped Si NCs with paralleled twin-crystal boundaries, and (d) epitaxial Si NCs near the Si(111) substrate
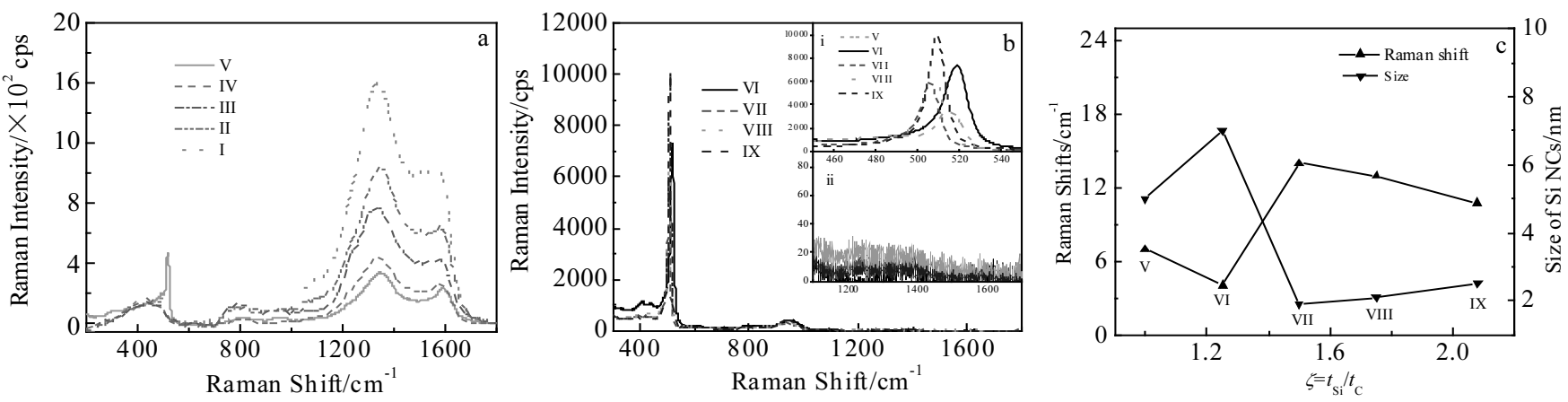

Fig.4 Raman spectra of annealed Si/C multilayer thin films: (a) samples I-V, (b) samples VI-IX (the insets (i) and (ii) are the magnified Si Raman peaks and C Raman peaks, respectively), and (c) the calculated results

peaks at 1350 and $1580 \mathrm{~cm}^{-1}$ correspond to the D-band and G-band of graphitic carbon ${ }^{[21]}$, respectively. With increasing $\zeta$, the Si NC Raman peak appears and is redshifted, as expected. At the same time, the $\mathrm{C}$ Raman peaks are weakened. A close-up view of Fig.4a indicates that when $\zeta$ is 1 , the Si NC Raman peak locates at $513.2 \mathrm{~cm}^{-1}$, and the intensities of the $\mathrm{C}$ peaks are weak. For samples with $\zeta$ greater than 1 , the $\mathrm{Si}-\mathrm{NC}$ peak intensity continues to strengthen, and the $\mathrm{C}$ peaks disappear (Fig.4b). These results suggest that $\mathrm{C}$ fully reacts with some of the $\mathrm{Si}$ to form $\alpha$-SiC, increasing the density of Si NCs. The Raman results are consistent with the GIXRD results.

Raman shifts can indicate changes in $\mathrm{Si}$ NC size. The Raman shifts of Si NCs samples V-IX are shown in the inset (i) of Fig.4b; the peaks are observed at 513.2, 518.7, 505.5, 507 , and $509 \mathrm{~cm}^{-1}$. The Si NC sizes of the different samples can be calculated according to ${ }^{[22,23]}$

$$
\Delta \omega=\omega(L)-\omega_{0}=-A(\alpha / L)^{\gamma}
$$

where $\omega(L)$ is the Raman frequency of a phonon in a NC with diameter $L, \omega_{0}$ is the frequency of an optical phonon at the zone center, and $a$ is the lattice constant of $\mathrm{Si}$. Parameters $A$ and $\gamma$ are used to describe the vibrational confinement due to the finite sizes of NCs. The calculated results are shown in Fig.4c. The sizes first increase and then decrease. That is, when $\zeta$ is in the range of 1 to 1.25 , the growth of Si NCs is confined by $\alpha$-SiC interlayers; when $\zeta$ is above 1.25 , both the nucleation center and the density of Si NCs rapidly increase and the results are shown in Fig.4c. The sizes first increase and then decrease. That is, when $\zeta$ is in the range of 1 to 1.25 , the growth of $\mathrm{Si} \mathrm{Si}$ NCs remain small because the coherent twin-crystal boundaries hinder the Si NC growth. These results are in agreement with the HRTEM observations.

\section{Conclusions}

1) Si NCs confined by an $\alpha$-SiC interlayer are prepared by the alternating deposition of $\mathrm{Si}$ and $\mathrm{C}$ layers with a fixed C-layer thickness of $10 \mathrm{~nm}$ followed by post-deposition annealing.

2) Based on GIXRD, HRTEM, and Raman analysis, heat facilitates changes in the layered structure and formation of $\mathrm{Si} \mathrm{NCs}$ and $\alpha$-SiC interlayers during annealing, and the crystallization and growth of Si NCs are self-adaptive under the constraining effect of the $\alpha-\mathrm{SiC}$ amorphous interlayer. For a fixed C-layer thickness of $10 \mathrm{~nm}$ in $\mathrm{Si} / \mathrm{C}$ multilayer films, the $\zeta$ around 1.25 represents a critical threshold. At $\zeta$ values less than or equal to 1.25 , the generated $\mathrm{Si}$ NCs mainly present quasi-spherical shapes with sizes of less than $7 \mathrm{~nm}$ and are separated by $\alpha$-SiC. At $\zeta$ values above 1.25, the $\mathrm{Si}$ NCs become brick-shaped and coherent 
twin-crystal boundaries develop between Si NCs. The method and results reported herein are expected to provide a promising route for $\mathrm{Si}$-based photo-electronic materials.

\section{References}

1 de Boer W D A M, Timmerman D, Dohnalová $\mathrm{K}$ et al. Nature Nanotechnology[J], 2010, 5: 878

2 Conibeer G, Perez-Wufl I, Hao X J et al. Nanoscale Research Letters[J], 2012, 7: 193

3 Priolo F, Gregorkiewicz T, Galli $\mathrm{M}$ et al. Nature Nanotechnology[J], 2014, 9: 19

4 Zhang $\mathrm{P}$, Zhang X W, Xu J et al. Nanoscale Research Letters[J], 2014, 9: 28

5 Wei Y, Huina F, Jin W et al. Physica B[J], 2014, 434: 177

6 Cheng Q J, Xu S Y, Ostrikov K. Acta Materials[J], 2010, 58: 560

7 Furuta K, Fujii M, Sugimoto $\mathrm{H}$ et al. Journal of Physical Chemistry Letters[J], 2015, 6: 2761

8 Schnabel M, Weiss C, Loper P et al. Physica Status Solidi $A[\mathrm{~J}], 2015,212: 1649$

9 Heitmann J, Muller F, Zacharias $\mathrm{M}$ et al. Advanced Materials $[\mathrm{J}], 2005,17: 795$

10 Ohba R, Yokohama T C. Electron Devices IEEE Transactions[J], 2000, 49: 313
11 El-Atab N, Turgut B B, Okyay A K et al. Nanoscale Research Letter[J], 2015, 10: 1

12 Arindam K, Partha C. AIP Advances[J], 2014, 4: 107106-13

13 Oliveira R A R, Ribeiro M, Pereyra I et al. Materials Characterization $[\mathrm{J}], 2003,50: 161$

14 Shigeru Y, Yasuyoshi K, Shinsuke M. Nanoscale Research Letter [J], 2014, 9: 1

15 Grom G F, Lockwood D J, McCaffrey J P et al. Nature [J], 2000, 407: 358

16 Conibeer G, Green M A, Corkish R. Thin Solid Films [J], 2006, 511-512: 654

17 Song D Y, Cho E C, Conibeer G et al. Journal of Applied Physics[J], 2008, 103: 083544

18 Kurokawa Y, Yamada S, Miyajima S et al. Current Applied Physics[J], 2010, 10: S435

19 Ding K, Aeberhard U, Astakhov O et al. Energy Procedia [J], 2011, 10: 249

20 Chang G R, Ma F, Xu K W et al. Nanotechnology[J], 2010, 21 : 465605

21 Li H T, Liu R H, Kong W Q. Nanoscale[J], 2014, 6: 867

22 Zi J, Büscher H, Falter C et al. Applied Physics Letters [J], 1996, 69: 200

23 Gupta S K, Jha P K. Solid State Communications[J], 2009, 149: 1989

\section{$\mathrm{Si} / \mathrm{C}$ 多层薄膜中硅纳米晶的微结构演化}

畅庚榕 ${ }^{1}$, 刘明霞 ${ }^{1}$, 马 飞 ${ }^{2}$, 付福兴 ${ }^{1}$, 何斌锋 ${ }^{1}$, 徐可为 ${ }^{1,2}$

(1. 西安文理学院 陕西省表面工程与再制造重点实验室, 陕西 西安 710065)

(2. 西安交通大学 金属材料强度国家重点实验室, 陕西 西安 710049)

摘 要: 通过磁控溅射技术和 $1100{ }^{\circ} \mathrm{C}$ 的高温后续退火处理, 在 $\mathrm{Si} / \mathrm{C}$ 多层薄膜中形成硅纳米晶。改变多层薄膜的 $\mathrm{Si} / \mathrm{C}$ 调制比 (ら) 可以调控 硅纳米晶的尺寸、形状和密度。其微观结构由小角X射线、拉曼频移、高分辨电镜进行表征。结合拉曼频移和高分辨透射电镜分析，得 到的结果表明, 由于受到 $\mathrm{C}$ 层界面约束, 非晶硅层在高温下会发生固态重结晶, 转变为纳米晶。通过 $\boldsymbol{\zeta}$ 可调控纳米晶的尺寸和形状。当 $\boldsymbol{\zeta}$ 从 0.5 到 2 改变时, 硅纳米晶的形状逐渐从球形、椭圆形转变为条形或者砖型。夹层受限生长模式有利于适应新一代硅基光电子器件的结 构设计。

关键词: 硅纳米晶; $\mathrm{Si} / \mathrm{C}$ 多层薄膜; 微结构; 拉曼频移

作者简介: 畅庚榕, 女, 1979 年生, 博士, 西安文理学院陕西省表面工程与再制造重点实验室, 陕西 西安 710065, 电话: 029-88258551, E-mail: gr_chang@163.com 